This item was submitted to Loughborough's Research Repository by the author.

Items in Figshare are protected by copyright, with all rights reserved, unless otherwise indicated.

\title{
The propensity for motorists to walk for short trips : evidence from West
}

\section{Edinburgh}

PLEASE CITE THE PUBLISHED VERSION

PUBLISHER

(c) Elsevier

LICENCE

CC BY-NC-ND 4.0

REPOSITORY RECORD

Ryley, Tim. 2019. "The Propensity for Motorists to Walk for Short Trips : Evidence from West Edinburgh". figshare. https://hdl.handle.net/2134/3694. 
This item was submitted to Loughborough's Institutional Repository (https://dspace.lboro.ac.uk/) by the author and is made available under the following Creative Commons Licence conditions.

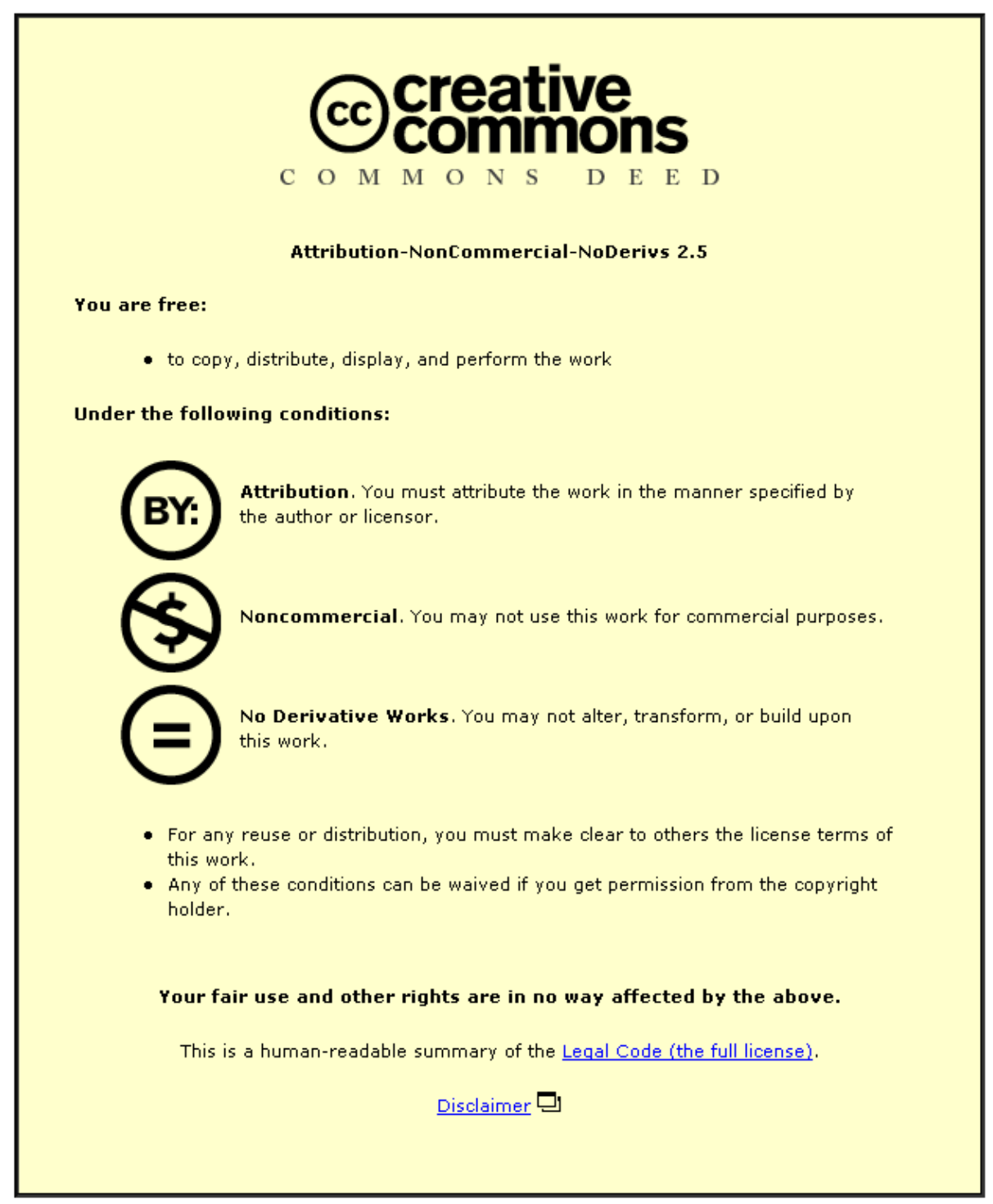

For the full text of this licence, please go to: http://creativecommons.org/licenses/by-nc-nd/2.5/ 
Loughborough University Institutional Repository paper. Original version submitted to: Ryley, T. (2008) The potential for car drivers to walk for short trips: evidence from West Edinburgh. Transportation Research - Part A: Policy \& Practice, 42 (4), pp. 620-628.

THE PROPENSITY FOR MOTORISTS TO WALK FOR SHORT TRIPS: EVIDENCE FROM WEST EDINBURGH

Dr Timothy John Ryley

Lecturer in Transport Studies

Transport Studies Group

Department of Civil and Building Engineering

Loughborough University

Leicestershire LE11 3TU

United Kingdom

Tel: +44 (0)1509 223422

Fax: $+44(0) 1509223981$

Email: T.J.Ryley@lboro.ac.uk

\begin{abstract}
The trade-offs individuals make between the motor car and walking for short trips are investigated, using data from a West Edinburgh household survey. Propensity to walk discrete choice models are estimated from a stated preference experiment within the survey questionnaire. This includes segmented models using socio-economic, spatial and attitudinal variables. The relative importance of the three attributes of journey time, petrol cost and parking cost are examined; value of time estimates are also generated.
\end{abstract}


Loughborough University Institutional Repository paper. Original version submitted to: Ryley, T. (2008) The potential for car drivers to walk for short trips: evidence from West Edinburgh. Transportation Research - Part A: Policy \& Practice, 42 (4), pp. 620-628.

With all other factors remaining constant, for short trips motorists are more likely to walk in response to an increase in parking costs than a rise in petrol prices. The use of parking as a transport policy tool is discussed.

\section{Key words}

Walking; stated preference; parking

\section{Introduction}

\subsection{Car dependency and the need to promote walking}

There are many undesirable by-products of motor car use, such as noise pollution, the construction of road infrastructure, the manufacture of vehicles, the disposal of vehicles, the usage of valuable fuel resources and the effects of road accidents. However, it can be argued that the two primary problems associated with the motor car are air pollution and congestion, representing the main thrust of United Kingdom transport policy documents (Department of the Environment, Transport and the Regions, 1998; Department for Transport, 2004a). As a result, contemporary transport policy aims to reduce motor car ownership and usage.

A range of policy measures can be implemented to try and reduce motor car ownership and usage. Stradling (2002) classifies measures to achieve travel behaviour change into two types. They are 'sticks' which constrain individuals in their transport choices, 
Loughborough University Institutional Repository paper. Original version submitted to: Ryley, T. (2008) The potential for car drivers to walk for short trips: evidence from West Edinburgh. Transportation Research - Part A: Policy \& Practice, 42 (4), pp. 620-628.

forcing them away from a mode, and 'carrots' which encourage individuals in their transport choices, enticing them towards a mode. Sticks tend to be concerned with increasing cost and decreasing availability. Examples include introducing road pricing, increasing petrol costs, increasing parking costs and banning motor cars from certain streets. Examples of carrots include the provision of sustainable transport facilities, improving public transport and marketing initiatives.

Of the transport modes promoted as alternatives to the motor car, walking represents the most sustainable form, without the pollution and congestion concerns of most other modes. Aside from being environmentally-friendly, walking is cheap, socially inclusive and provides exercise and health benefits. However, the main disadvantage with walking is that it is the slowest mode, usually confined to short trips.

The Integrated Transport White Paper "Transport: A new deal" (Department of the Environment, Transport and the Regions, 1998), represented a change in United Kingdom Government transport policy, with a strong emphasis on non-motorised modes (walking and cycling). An underlying theme of the White Paper is to reduce the travel need of individuals, achieved by encouraging a modal shift to sustainable transport modes such as non-motorised modes, and reducing car dependency. Walking measures local authorities are encouraged to implement from the Integrated Transport White Paper have been categorised and are shown in Table 1; most walking measures relate to facilities for pedestrians. As Gaffron (2000) shows from a survey of British local authorities, there has been an increase towards non-motorised modes in local authority transport policy. Many now have their own cycling and walking strategies. 
Loughborough University Institutional Repository paper. Original version submitted to: Ryley, T. (2008) The potential for car drivers to walk for short trips: evidence from West Edinburgh. Transportation Research - Part A: Policy \& Practice, 42 (4), pp. 620-628.

Therefore much of the impetus of national United Kingdom transport policy depends on local authorities and it is the implementation of sustainable transport initiatives at a local level that has arguably been one of the main successes of the United Kingdom Integrated Transport Strategy over the last ten year or so (Tolley, 2003). It is local level initiatives such as Safer Routes to School, Green Transport Plans, “walking buses” (groups of individuals, typically children, walk together) and car free days that could prove important to an increase in non-motorised mode use.

However, policy initiatives to encourage walking are not as advanced as cycling policy initiatives. It was intended to develop a National Walking Strategy (Department of Transport, 1996a) similar to the National Cycling Strategy (Department of Transport, 1996b), but the resultant policy document is an advice note on walking to Local Authorities in England (Department of the Environment, Transport and the Regions, 2000). It emphasises the provision of a high quality network consisting of peoplefriendly facilities, with supporting policy, development planning and promotion measures. The document's cautious introduction states that walking policy initiatives will not make much difference to car mileage, air pollution or global warming, although the effects will be positive.

That said, the walking and cycling action plan (Department for Transport, 2004b) provides practical walking action points in the areas of improving the environment through planning, providing facilities and influencing travel behaviour. Initiatives include improving personal safety and anti-social behaviour; street design with more of 
Loughborough University Institutional Repository paper. Original version submitted to: Ryley, T. (2008) The potential for car drivers to walk for short trips: evidence from West Edinburgh. Transportation Research - Part A: Policy \& Practice, 42 (4), pp. 620-628.

a focus on people; and influencing travel behaviour through marketing and education. The action plan also has more of an emphasis towards health than previous nonmotorised mode policy.

Despite the lack of a change in the level of non-motorised mode use and an increase in the emphasis of policy back towards road building (Department for Transport, 2004a), non-motorised modes remain high on the United Kingdom policy agenda. This is partly due to the support of non-motorised modes through associated social inclusion, health, exercise, obesity, transport planning and sustainable development policy.

\subsection{The development of discrete choice transport models using stated preference} data

Up to the mid-1980s, transportation models exclusively used revealed preference data, based on observed choices and decisions. Interest arose in theories and methods from behavioural sciences, and stated preference data has since been incorporated into transportation applications to complement revealed preference data. Stated preference techniques present hypothetical choices to an individual, measuring how a respondent's choices vary as circumstances change. The main advantage of stated preference based techniques is that they allow testing under experimental conditions. There are some disadvantages with stated preference techniques. These include the difficulties to predict efficiently and to validate the results. Reviewing other studies, Polak and Jones (1997) show that stated preference studies typically over-estimate forecasts and emphasise the need for validation. Crucially, it is unclear as to whether respondents 
Loughborough University Institutional Repository paper. Original version submitted to: Ryley, T. (2008) The potential for car drivers to walk for short trips: evidence from West Edinburgh. Transportation Research - Part A: Policy \& Practice, 42 (4), pp. 620-628.

would actually make the decision to change mode. They may state something in the experiment but act differently in practice.

Discrete choice models using stated preference data concern the choices individuals make from a set of mutually exclusive and collectively exhaustive alternatives; the theoretical background to discrete choice modelling is random utility theory (Ben-Akiva and Lerman, 1985; Louviere et al, 2000). Random utility theory was originally developed in the field of transport using operational binary choice models. These models were expanded in the 1970s to other travel related choices such as trip destination, trip frequency, car ownership and residential location. Using a choice set of more than two alternatives, multinomial logit models were developed. Thus, nonmotorised modes (cycling and walking) could be incorporated alongside the typically used modes of the motor car and bus. Non-motorised mode choice modelling research has focused on cycling rather than walking (Wardman et al, 1997; Wardman et al, 2000; Ortuzar et al, 2000). An original contribution of this paper is the discrete choice modelling on the choice between walking and taking the motor car, using stated preference data.

\subsection{The case study of Edinburgh}

As a compact, high-density city, Edinburgh is particularly suited to walking. Indeed, levels of walking are relatively high in Edinburgh in comparison with other United Kingdom cities, using 2001 Census data (City of Edinburgh Council, 2003). Edinburgh has very high walking levels for the journey to work or study (20.8\%); of the 42 United 
Loughborough University Institutional Repository paper. Original version submitted to: Ryley, T. (2008) The potential for car drivers to walk for short trips: evidence from West Edinburgh. Transportation Research - Part A: Policy \& Practice, 42 (4), pp. 620-628.

Kingdom cities listed, only Norwich (22.7\%) and Dundee (21.4\%) have higher levels. Furthermore, of the United Kingdom cities Edinburgh has the highest bus use to work or study (26.2\%), although unlike many other cities does not have an underground or tram system.

Local policy-makers in Edinburgh have strongly promoted a sustainable transport policy. The Local Transport Strategy for Edinburgh (City of Edinburgh Council, 2004) recognises that the city cannot accommodate unlimited growth in motor car use. Walking promotion includes the Central Edinburgh Traffic Management Scheme, in which traffic has been banned from certain central streets and the area has become more pedestrian-friendly. Signal phases at pedestrian crossings have also become more favourable to pedestrians wishing to cross.

This paper presents results from a West Edinburgh household survey, the second of a two-stage data collection as part of a $\mathrm{PhD}$ thesis focusing on the propensity of individuals to walk and cycle in Edinburgh (Ryley, 2005). The first collection stage concerns a secondary data set, the Scottish Household Survey; an Edinburgh sample was obtained consisting of socio-economic, transport and travel information on 2,910 households. Using cluster analysis on the Scottish Household Survey data, population segments were developed, primarily linked to life stage and based on current socioeconomic characteristics. The impacts upon individual non-motorised mode travel behaviour, for each population segment, have been analysed (Ryley, 2006a). 'Students', those 'in-between jobs' and 'part-timers without children' have the greatest 
Loughborough University Institutional Repository paper. Original version submitted to: Ryley, T. (2008) The potential for car drivers to walk for short trips: evidence from West Edinburgh. Transportation Research - Part A: Policy \& Practice, 42 (4), pp. 620-628.

propensity use non-motorised modes; those in retirement, as well as 'high earners without children', have the least propensity to use non-motorised modes.

\section{The West Edinburgh household survey}

\subsection{Survey design}

The West Edinburgh household survey was conducted in July 2003. There were 3,000 questionnaires delivered to four chosen postcode sectors at regular distances from the centre of Edinburgh, along a transport corridor approximately 0-2km, 2-4km, 4-6km and 6-8km. In order of distance from the centre, the postcode sector areas were: Dalry, Slateford, Wester Hailes and Currie. Each postcode sector area had three households randomly selected from the Electoral Register. A sub-area was defined as the 250 households sampled in close proximity to the three randomly selected households. The sampling strategy, therefore, concerned a combination of clustered and stratified random sampling to cut down on field costs.

The data collection technique used was the 'call and post' method. Delivery of selfcompletion questionnaires was on weekday evenings Monday to Thursday, when household members were more likely to be at home. Survey staff 'called' on a household with a questionnaire, asking them to complete the questionnaire, and 'post' it back at their own convenience using an enclosed pre-paid return envelope. It was desirable to sample every household within a sub-area, including those not at home when the survey staff called. Calling on a household, therefore, involved either handing 
Loughborough University Institutional Repository paper. Original version submitted to: Ryley, T. (2008) The potential for car drivers to walk for short trips: evidence from West Edinburgh. Transportation Research - Part A: Policy \& Practice, 42 (4), pp. 620-628.

over a questionnaire on the doorstep if the individual agreed to take part in the survey, or posting the questionnaire (and pre-paid envelope) through the letter-box if the householder was not at home.

The survey questionnaire included revealed preference questions relating to socioeconomic information, background transport characteristics and attitudinal data. There were two stated preference experiments. Aside from the propensity to walk stated preference experiment, reported in this paper, there is a propensity to cycle stated preference experiment for the journey to work or study (see Ryley, 2006b).

\subsection{A summary of the sample}

Of the 3,000 questionnaires delivered, there are 997 returns, representing an overall response rate of $33 \%$. The large sample size enables segmentation to be undertaken and the development of robust discrete choice models. The size also compensates for spatial and non-response bias within the survey.

The area distribution of 990 respondents is as follows (seven returned questionnaires were missing area identifiers): 221 from Dalry (22\%), 311 from Slateford (31\%), 169 from Wester Hailes (17\%) and 289 in Currie (29\%). There is a very different response rate between areas and streets; response rates are greater in sub-areas containing higher income households and lower density housing. The lower response rates in high density housing sub-areas may be due to difficulties in accessing the stair entrance, and that in flats the household is more likely to be out at the time of call. 
Loughborough University Institutional Repository paper. Original version submitted to: Ryley, T. (2008) The potential for car drivers to walk for short trips: evidence from West Edinburgh. Transportation Research - Part A: Policy \& Practice, 42 (4), pp. 620-628.

Amongst the sample, there are 560 car drivers who drive "most days” (63\%).

Representation amongst this group is related particularly to certain income brackets and postcode sector areas. A comparison of the income bands shows that the proportion of the sample driving most days steadily rises through the seven income bands from $33 \%$ in the lowest income band (household income of less than $£ 6,000$ ) through to $74 \%$ in the highest income band (household income of more than $£ 40,000$ ). Individuals living further out from the centre of Edinburgh are more likely to drive “most days” (37\% in the Dalry postcode sector up to $77 \%$ in the Currie postcode sector).

\section{Discrete choice model estimation of the propensity to walk stated preference experiment}

\subsection{Stated preference experiment design}

In the absence of previously published work examining walking trade-offs, a simple stated preference experiment of nine scenarios has been designed using three time and cost variables. These attributes are journey time, petrol or diesel price, and the cost of parking at the destination. Time and cost values associated with the motor car and public transport are typically used in the mode choice element within traditional fourstage models, and were adapted for trade-offs between taking the motor car and walking. The cost values of car parking and fuel price are topical transport 'stick' policy measures, forcing motorists to reduce their motor car usage. 
Loughborough University Institutional Repository paper. Original version submitted to: Ryley, T. (2008) The potential for car drivers to walk for short trips: evidence from West Edinburgh. Transportation Research - Part A: Policy \& Practice, 42 (4), pp. 620-628.

The choice set for a given journey is solely between the motor car and walking. Therefore, only current car drivers are considered for the experiment. The journey presented to respondents is one from their home to a destination in and around Edinburgh. Assumptions are provided: the respondent is travelling on their own, has nothing to carry, and the weather is dry. These make the trade-off between the motor car and walking more likely, because otherwise the motor car dominates choices. The journey time in the experiment is ten minutes door to door by motor car, representing a short trip in and around Edinburgh.

The base price of petrol or diesel is 80p per litre, an approximation of the price at the time of the survey. Parking costs appropriate to Edinburgh were designated, in that parking may or may not incur a charge. It should be noted that these costs, unlike car insurance or depreciation of vehicle, are up-front in the sense that an individual notices every time they pay. The attribute levels in a pilot survey of 58 households resulted in respondents tending to choose cost over time. Therefore, the cost values were reduced in the final form of the West Edinburgh survey to ensure respondents make realistic choices.

The three attributes for the propensity to walk stated preference experiment, shown as differences between the two modes, are as follows:

- Door to door journey time: 10 minutes for all motor car choices; 15 minutes, 20 minutes and 30 minutes for the walking choices. This represents an extra journey time of 5 minutes, 10 minutes and 20 minutes to walk. 
Loughborough University Institutional Repository paper. Original version submitted to: Ryley, T. (2008) The potential for car drivers to walk for short trips: evidence from West Edinburgh. Transportation Research - Part A: Policy \& Practice, 42 (4), pp. 620-628.

- $\quad$ Petrol or diesel price: No cost for all walking choices; 80p, $£ 1$ and $£ 2$ petrol costs for the motor car choices. This represents an extra cost of 80p, $£ 1$ and $£ 2$ to travel by motor car.

- $\quad$ Cost of parking car at destination: No cost for all walking choices; no cost, £2 and $£ 5$ parking charge for the motor car choices. This represents no extra cost, £2 extra and $£ 5$ extra to travel by motor car.

The propensity to walk model estimation can be put into perspective by comparing results against those for the Edinburgh population using Scottish Household Survey travel diary data, collected as part of the stage one data collection. The stated preference experiment for the propensity to walk considers journeys taking between 10 and 30 minutes on foot. It assumes that the respondent has a motor car available and is able to walk. In the Scottish Household Survey travel diary, 32.2\% of trips are of the required distance (taking between 10 and 30 minutes on foot), for $60.8 \%$ of trips a motor car is available to the individual, and for $98.7 \%$ of trips the individual is fit to walk (not a Blue Badge holder). From these three values, 19\% of trips would be relevant for the motor car and walking trade-off stated preference experiment. In reality, the proportion would be less. The data does not enable the other three prerequisites from the stated preference experiment to be incorporated: the individual has nothing to carry, is travelling on their own and the weather is dry.

\subsection{Model estimation for the motorist sample}


Loughborough University Institutional Repository paper. Original version submitted to: Ryley, T. (2008) The potential for car drivers to walk for short trips: evidence from West Edinburgh. Transportation Research - Part A: Policy \& Practice, 42 (4), pp. 620-628.

Of the total survey sample of 997 respondents, 627 eligible car drivers completed the stated preference experiment. Motorists in the sample typically drive most days, are from higher income households and live towards the edge of the urban area. Of the 5,643 stated choices (each respondent has nine scenarios), the walk option is chosen on 4,303 occasions, the motor car option on 1,340 occasions. This represents sufficient trade-offs between the two modes for modelling purposes.

Outputs from the model estimation of the total motorist sample are shown in Table 2. In terms of model robustness, the rho-squared value with respect to zero is 0.3094 . A high rho-squared value in the propensity to walk experiment could reflect the higher number of cases and the simplicity of the experiment (three variables for journey time, petrol costs and parking costs).

Each of the three attributes significantly affects the model, since the T values are greater than 1.96, a 95\% confidence level. T value signs are negative, to be expected for time, petrol costs and parking costs in the binary mode choice context, since an individual's relative utility increases with a decrease in any of these three attributes. The order of influence of the attributes on the model is parking costs, journey time and then petrol costs. Petrol costs have a considerably lower relative influence upon the choice between the motor car and walking.

\subsection{Value of time outputs}


Loughborough University Institutional Repository paper. Original version submitted to: Ryley, T. (2008) The potential for car drivers to walk for short trips: evidence from West Edinburgh. Transportation Research - Part A: Policy \& Practice, 42 (4), pp. 620-628.

As Louviere et al (2000, p. 61) state, “increasingly discrete-choice models are being used to derive estimates of the amount of money an individual is willing to pay (or willing to accept) to obtain some benefit (or avoid some cost) from a specific action.” The ratio of two utility parameters provides a willingness to pay measure, holding all other potential influences constant; in this study it relates to the willing to pay against the journey time in the experiment. Values of time for petrol and parking costs are 23.6p per minute and 28.9p per minute respectively. Respondents put a higher value of time on parking costs than petrol prices. As a comparison, the most recent non-working value of time 'market type' figures from the Department for Transport, calculated from the National Travel Survey, are 8.4p for commuting trips and 7.4p (calculated from $£$ per hour) for other trips (Department for Transport, 2004c - Table 2). The trip for the propensity to walk stated preference experiment is not specified, although it is more likely to be a non-working journey.

More disaggregate values of time than the Department for Transport (2004c) figures are not available. Although the United Kingdom non-working values of time are much lower than the West Edinburgh survey values, there are three key differences between the two data sources. Firstly, the national data covers all United Kingdom areas, but data from the West Edinburgh survey concerns an urban area where the values of time are expected to the higher. Secondly, the United Kingdom values of time concern all modes, whereas the West Edinburgh survey focuses on motor car choices (trading-off against walking choices). Motorists are expected to have a higher value of time than other transport modes. Thirdly, it is to be expected that values of time associated with parking and petrol costs would be higher than the United Kingdom value of time 
Loughborough University Institutional Repository paper. Original version submitted to: Ryley, T. (2008) The potential for car drivers to walk for short trips: evidence from West Edinburgh. Transportation Research - Part A: Policy \& Practice, 42 (4), pp. 620-628.

figures, which concern all travel costs. The reluctance for individuals to change mode away from the motor car in response to an increase in petrol prices was shown in the attitudinal section of the questionnaire; only $16 \%$ of the 622 car drivers in the West Edinburgh sample would consider or use alternatives to the motor car for a 25\% increase in petrol (and diesel) prices.

The discrepancies could also be explained by problems associated with global values of time. One study comparing stated preference and revealed preference outputs (Wardman, 1988), has shown discrepancies can exist with global stated preference values of time. It is acknowledged that the value of time outputs from the propensity to walk discrete choice models are from a specific transport choice situation (i.e. between the motor car and walking), and so some care needs to be taken interpreting the values of time generated. As Ortuzar and Willumsen (2001: p457) state, "subjective values of time are heavily dependent on model specification and data; this is an undesirable property because consistent evaluation of projects is sought over a wide range of models and areas.”

\subsection{Model segmentation}

This modelling approach use a segmented sample rather than the total motorist sample, to focus on the relative importance different population segments place on attributes. Due to the large size of the motorist sample (627 respondents), it has been possible to run many different segmented models. The following socio-economic, spatial and 
Loughborough University Institutional Repository paper. Original version submitted to: Ryley, T. (2008) The potential for car drivers to walk for short trips: evidence from West Edinburgh. Transportation Research - Part A: Policy \& Practice, 42 (4), pp. 620-628.

attitudinal segmentation variables within the West Edinburgh survey have been used to segment the model estimation:

- Age;

- Gender;

- Income;

- House type;

- Key life stages identified from the cluster analysis of the Scottish Household Survey data (i.e. having children, in employment and retired);

- Disability of the respondent or a member of the household (if there is a Blue badge holder within the household);

- $\quad$ Postcode sector area;

- Attitudinal variables (responses to petrol and parking policies);

- Population segments identified from the cluster analysis of the Scottish Household Survey data; and

- Population segment split by postcode sector area.

Each segment model consists of at least 25 individuals, considered as a minimum for the discrete choice modelling. If a variable has many categories, such as income, those at the extremes are the segments used (e.g. $£ 15,000$ p.a. or less and more than $£ 40,000$ p.a.), enabling variations to be more visible. Results from the segmented models are shown in Table 3. 
Loughborough University Institutional Repository paper. Original version submitted to: Ryley, T. (2008) The potential for car drivers to walk for short trips: evidence from West Edinburgh. Transportation Research - Part A: Policy \& Practice, 42 (4), pp. 620-628.

Almost all of the T values are significant at the 95\% level (the petrol cost attribute of the Blue badge in the household model is not significant). As with the model of the total motorist sample, the two attributes with the greatest influence amongst the segmented models (with higher relative T values) are journey time and parking cost. There is, however, a distinct difference between the primary attribute amongst the segmented models.

Parking cost is the most influential attribute for women, those living in flats and those on low incomes (£15,000 per annum or less). Journey time is the most influential attribute for men, those on high incomes (over $£ 40,000$ per annum), those living in detached houses, those in full-time employment and those in retirement. The results for these segments are generally to be expected, since these population segments tend to have a higher value of time (Wardman, 1998). The exception would perhaps be those in retirement, although this group has the most marginal difference between journey time and parking cost.

Although petrol cost is a much less influential attribute, those on low incomes (less than $£ 15,000$ per annum) and those in retirement are the most sensitive to fuel price increases. This is as expected (Black, 2000). The age, Blue Badge and presence of children segments do not affect the relative importance of the attributes.

Segmented models have been run using some of the attitudinal variables to validate respondent choices. The responses to the petrol price change (segmenting those that would definitely give up using the motor car at a $£ 2$ petrol price) and parking policy 
Loughborough University Institutional Repository paper. Original version submitted to: Ryley, T. (2008) The potential for car drivers to walk for short trips: evidence from West Edinburgh. Transportation Research - Part A: Policy \& Practice, 42 (4), pp. 620-628.

(segmenting those that would change motor car usage in response to parking policy) questions provided results as expected: these segments showed greater sensitivity to the petrol price and parking cost variables respectively.

\section{Discussion and conclusions}

With all other factors remaining constant, for short trips motorists are more likely to walk in response to an increase in parking costs than a rise in petrol prices. This is illustrated by the level of relative attributes for the model estimation of the total motorist sample. Not only are individuals more responsive to the parking cost increases, but parking policy measures are less likely to receive a public protest and can be varied spatially. This enables the targeting of specific areas or population segments.

Parking charges in Edinburgh can be time dependent (e.g. 20p for 20 minutes), linked to the cost of a residential permit, or free of charge. It is acknowledged that the length of time an individual will stay parking at the destination is not specified in the stated preference experiment. The destination of the trip is also not specified; it could be onstreet or in an off-street car park. This would affect modal choice between the motor car and walking. However, realistic parking levels of no charge, $£ 2$ or $£ 5$ were set in the stated preference experiment; model estimation shows the reliability of these levels.

Some contemporary parking policies are to be commended. For example, transport planning policy guidance (Department of the Environment, Transport and the Regions, 2001; Scottish Office, 1999) recommends maximum parking standards for new 
Loughborough University Institutional Repository paper. Original version submitted to: Ryley, T. (2008) The potential for car drivers to walk for short trips: evidence from West Edinburgh. Transportation Research - Part A: Policy \& Practice, 42 (4), pp. 620-628.

development, whilst the City of Edinburgh Council has been extending the Controlled Parking Zone (City of Edinburgh Council, 2004). Designing and reviewing controlled parking zones also represents an opportunity to improve the pedestrian environment. Parking policy should be reinforced and extended to reduce motor car usage. It could have more emphasis on the level of charge, in addition to the control of supply and the enforcement of regulations. For instance, minimum parking charges could be set within transport policy, at both national and local levels.

Parking and petrol cost increases represent stick measures, constraining motor car usage. Such policy measures should be balanced with carrot policy measures to encourage walking. Examples to encourage walking include improving the pedestrian environment, developing car-free zones and improving signal timings for pedestrians.

Segmented models show the population groups most affected by a rise in parking cost for short trips: women, those living in flats and those on low incomes $(£ 15,000$ per annum or less). These groups have a lower value of time and are the least car dependent. Also shown from the segment models are the expected results of those most sensitive to a rise in petrol costs, namely those on low incomes ( $£ 15,000$ per annum or less) and those in retirement.

Value of time outputs have been generated from the model estimation of the overall sample; they appear reasonable given that any differences are due to the unique nature of the propensity to walk stated preference experiment (i.e. binary mode choice of the motor car versus walking for short trips in an urban area). 
Loughborough University Institutional Repository paper. Original version submitted to: Ryley, T. (2008) The potential for car drivers to walk for short trips: evidence from West Edinburgh. Transportation Research - Part A: Policy \& Practice, 42 (4), pp. 620-628.

The propensity to walk discrete choice modelling represents a tentative approach in a new study area. The modelling effort could be developed further to include walkingrelated attributes such as footway provision and (safe and convenient) road crossings. More advanced model functions for the propensity to walk could be developed, including an extension into joint revealed-stated preference data modelling to generate robust forecasts.

\section{ACKNOWLEDGEMENTS}

This paper is based upon PhD research conducted at Napier University, Edinburgh. The author would like to thank Professor Austin Smyth as his Director of Studies and Dr Tom Rye as his Supervisor for their comments, support and encouragement throughout the $\mathrm{PhD}$.

\section{REFERENCES}

Ben-Akiva, M., and Lerman, S. (1985) Discrete Choice Analysis: Theory and Application to Travel Demand. MIT press, Cambridge.

Black, W.R. (2000) Socio-economic barriers to sustainable transport. Journal of Transport Geography, 8, pp. 141-147. 
Loughborough University Institutional Repository paper. Original version submitted to: Ryley, T. (2008) The potential for car drivers to walk for short trips: evidence from West Edinburgh. Transportation Research - Part A: Policy \& Practice, 42 (4), pp. 620-628.

City of Edinburgh Council (2003) Edinburgh’s Census 2001 City Comparisons. City Development Department Research Section, the City of Edinburgh Council, Edinburgh.

City of Edinburgh Council (2004) Local Transport Strategy 2004-2007. The City of Edinburgh Council, Edinburgh.

Department for Transport (2004a) The future of transport: a network for 2030. July 2004. HMSO, London.

Department for Transport (2004b) Walking and cycling: an action plan. June 2004. HMSO, London.

Department for Transport (2004c). Values of time and operating costs. Transport Analysis Guidance (TAG) Unit 3.5.6, Department for Transport. December 2004. HMSO, London.

Department of the Environment, Transport and the Regions (1998) A New Deal for Transport: Better for Everyone, The Government's White Paper on the Future of Transport. HMSO, London.

Department of the Environment, Transport and the Regions (2000) Encouraging walking: advice to local authorities. HMSO, London. 
Loughborough University Institutional Repository paper. Original version submitted to: Ryley, T. (2008) The potential for car drivers to walk for short trips: evidence from West Edinburgh. Transportation Research - Part A: Policy \& Practice, 42 (4), pp. 620-628.

Department of the Environment, Transport and the Regions. (2001) Planning Policy

Guidance 13. Transport. HMSO, London.

Department of Transport (1996a) National Cycling Strategy. HMSO, London.

Department of Transport (1996b) Developing a Strategy for Walking. HMSO, London.

Gaffron, P. (2000) Walking and cycling - does common neglect equal common interests. World Transport Policy and Practice, 6 (3), pp. 9-14.

Louviere, J.J., Hensher, D.A. and Swait, J.D. (2000) Stated choice methods. Analysis and application. Cambridge University Press.

Ortuzar, J.D., Iacobelli, I. and Valeze, C. (2000) Estimating demand for a cycle network. Transportation Research Part A, 34, pp. 353-373.

Ortuzar, J. and Willumsen, L.G. (2001) Modelling Transport. Third edition. Wiley, Chichester.

Polak, J., and Jones, P. (1997) Using stated-preference methods to examine traveller preferences and responses. In Understanding Travel Behaviour in an Era of Change (ed. P Stopher and M Lee-Gosselin). 
Loughborough University Institutional Repository paper. Original version submitted to: Ryley, T. (2008) The potential for car drivers to walk for short trips: evidence from West Edinburgh. Transportation Research - Part A: Policy \& Practice, 42 (4), pp. 620-628.

Ryley, T.J. (2005) A study of individual travel behaviour in Edinburgh, to assess the propensity to use non-motorised modes. Ph.D. thesis, Napier University.

Ryley, T.J. (2006a) 'Use of non-motorised modes and life stage: evidence from Edinburgh’, Journal of Transport Geography, 14 (5), pp. 367-375.

Ryley, T.J. (2006b) Estimating cycling demand for the journey to work or study in West Edinburgh. Paper presented at the $85^{\text {th }}$ Annual Meeting of the Transportation Research Board, Washington, DC, 22-26 January 2006.

Scottish Office. (1999) National Planning Policy Guideline: NPPG17. April 1999. The Scottish Office, Edinburgh.

Stradling, S.G. (2002) Persuading people out of their cars. Napier University Professorial Lecture. Napier University.

Tolley, R. (2003) Ubiquitous, everyday walking and cycling: the acid test of sustainable transport policy, Chapter 8 in Docherty, I. and Shaw, J. (eds) A new deal for transport? RGS-IBG Book Series, Blackwell.

Wardman, M., 1988. A comparison of revealed preference and stated preference models of travel behaviour. Journal of Transport Economics and Policy, 22 (1), pp. 7191. 
Loughborough University Institutional Repository paper. Original version submitted to: Ryley, T. (2008) The potential for car drivers to walk for short trips: evidence from West Edinburgh. Transportation Research - Part A: Policy \& Practice, 42 (4), pp. 620-628.

Wardman, M. (1998) The Value of Travel Time: A Review of British Evidence.

Journal of Transport Economics and Policy, 32 (3), pp. 285-315.

Wardman, M., Hatfield, R. and Page, M. (1997) The UK national cycling strategy: can improved facilities meet the targets? Transport Policy, 4 (2), pp. 123-133.

Wardman, M., Nash C.A., Tight M.R. and Page M.W. (2000) Cycling and urban mode choice, Final report of ESRC project R000237103. 
Loughborough University Institutional Repository paper. Original version submitted to: Ryley, T. (2008) The potential for car drivers to walk for short trips: evidence from West Edinburgh. Transportation Research - Part A: Policy \& Practice, 42 (4), pp. 620-628.

\section{TABLES}

Table 1. Categories of walking measures Local Authorities are encouraged to implement from the Integrated Transport White Paper

\begin{tabular}{ll}
\hline Category & Walking measure \\
Facilities & $\begin{array}{l}\text { 1. Reallocate road space to pedestrians, e.g. } \\
\text { wider pavements \& pedestrianisation } \\
\text { 2. Provide more direct \& convenient routes } \\
\text { for walking } \\
\text { 3. Improve footpath maintenance \& } \\
\text { cleanliness } \\
\text { 4. Provide more pedestrian crossings } \\
\text { 5. Reduce waiting times for pedestrians at } \\
\text { traffic signals \& give them priority at } \\
\text { junctions } \\
\text { 6. Deal with characteristics of traffic that } \\
\text { deter people from walking } \\
\text { 7. Introduce traffic calming measures near } \\
\text { schools, in 'home zones' \& in selected country } \\
\text { lanes } \\
\text { 8. Use planning powers to ensure that the } \\
\text { land use mix, layout \& design of } \\
\text { development is safe, attractive \& convenient } \\
\text { for walking }\end{array}$ \\
\hline
\end{tabular}

Source: Department of the Environment, Transport and the Regions (1998) 
Loughborough University Institutional Repository paper. Original version submitted to: Ryley, T. (2008) The potential for car drivers to walk for short trips: evidence from West Edinburgh. Transportation Research - Part A: Policy \& Practice, 42 (4), pp. 620-628.

Table 2. Outputs from the propensity to walk model estimation of the total motorist sample

Number of respondents

Number of SP choices

Rho squared $\left(\mathrm{r}^{2}\right)$ with respect to zero

Rho squared $\left(\mathrm{r}^{2}\right)$ with respect to the constant

\section{7}

5643

0.3094

0.1267

\begin{tabular}{lll} 
Attribute & Coefficient & T value \\
time & -0.09822 & -18.1 \\
petrol & -0.4159 & -6.3 \\
parking & -0.3399 & -18.5 \\
constant & 1.205 & 10.4 \\
\hline
\end{tabular}


Loughborough University Institutional Repository paper. Original version submitted to: Ryley, T. (2008) The potential for car drivers to walk for short trips: evidence from West Edinburgh. Transportation Research - Part A: Policy \& Practice, 42 (4), pp. 620-628.

Table 3. Results for the propensity to walk stated preference experiment, by individual segmentation variables

\begin{tabular}{|c|c|c|c|c|c|}
\hline $\begin{array}{l}\text { Segmentation model, in comparison } \\
\text { with the total motorist sample }\end{array}$ & Number & $\begin{array}{l}\mathbf{r}^{2}-\text { with } \\
\text { respect to } \\
\text { zero }\end{array}$ & $\begin{array}{l}\text { T value: } \\
\text { time }\end{array}$ & $\begin{array}{l}\text { T value: } \\
\text { petrol }\end{array}$ & $\begin{array}{l}\text { T value: } \\
\text { park }\end{array}$ \\
\hline Age - under 35 & 126 & 0.3442 & -7.4 & -2.5 & -9.8 \\
\hline Age - 65 and over & 135 & 0.2282 & -6.5 & -2.9 & -7 \\
\hline Gender - male & 347 & 0.3222 & -14.9 & -5.4 & -14.4 \\
\hline Gender - female & 277 & 0.2970 & -10.5 & -3.4 & -11.6 \\
\hline Income $-£ 15,000$ pa or less & 102 & 0.2673 & -4.9 & -3.1 & -6.6 \\
\hline Income - more than $£ 40,000$ pa & 166 & 0.3210 & -10.8 & -2.5 & -9.8 \\
\hline Children - in household & 172 & 0.3613 & -9.9 & -3.6 & -10.4 \\
\hline Children - not in household & 455 & 0.2915 & -15.2 & -5.2 & -15.4 \\
\hline House type - detached & 186 & 0.2742 & -10.4 & -3.1 & -9.8 \\
\hline House type - flat & 169 & 0.3668 & -9.4 & -3.6 & -10.1 \\
\hline Situation of respondent - employed full-time ${ }^{1}$ & 306 & 0.3490 & -14.9 & -4.5 & -14.1 \\
\hline Situation of respondent - retired & 159 & 0.2624 & -7.4 & -3.5 & -7.3 \\
\hline Blue badge - in household & 31 & 0.0722 & -2.5 & -1.2 & -2.9 \\
\hline Blue badge - not in household & 596 & 0.3293 & -18.1 & -6.1 & -18.4 \\
\hline Total motorist sample & 627 & 0.3094 & -18.1 & -6.3 & -18.5 \\
\hline
\end{tabular}

Note: ${ }^{1}=$ not self-employed 